\title{
Non-destructive and rapid discrimination of hard-to-cook beans using hyperspectral imaging
}

\author{
Lina M. Diaz-Contreras, Chyngyz Erkinbaev and Jitendra Paliwal \\ Department of Biosystems Engineering, University of Manitoba, Winnipeg, MB R3T 5V6, Canada \\ Corresponding Author: Jitendra Paliwal (J.Paliwal@umanitoba.ca)
}

\begin{abstract}
Dry beans stored under sub-optimal conditions tend to develop hard-to-cook (HTC) defect, which extends the cooking time making them less palatable while reducing their nutritional value. The current methods of identifying HTC beans are time-consuming, destructive, and unreliable. A rapid non-destructive inspection technique for prescreening beans could help identify and discard HTC beans prior to processing. To this end, the potential of hyperspectral imaging technique covering the entire visible to near infrared (NIR) spectral range (400-2500 nm) was evaluated for rapid and non-destructive identification of HTC beans. The HTC phenomenon was artificially induced in healthy white beans using two different combinations of suboptimal storage conditions of temperature and relative humidity $\left(35^{\circ} \mathrm{C}, 75 \% \mathrm{RH}\right.$ for 45 days and $60^{\circ} \mathrm{C}, 75 \% \mathrm{RH}$ for 10 days). Subsequently, the beans were cooked for specified durations and their hardness measured using a texture analyzer. The HTC and control (i.e. easy-to-cook (ETC)) beans were scanned with push-broom hyperspectral imaging systems. Results indicate that both sets of storage conditions rendered the beans HTC but the phenomenon induced by the two different methods was detected in different spectral ranges using hyperspectral imaging. Wavelengths across the entire visible and NIR ranges of electromagnetic spectrum were found useful in detecting HTC as beans stored at $35^{\circ} \mathrm{C}$ and $75 \% \mathrm{RH}$ for 45 days were identified mainly in the $1000-2500 \mathrm{~nm}$ range and those stored at $60^{\circ} \mathrm{C}$ and $75 \% \mathrm{RH}$ for 10 days were identified in the $400-1000 \mathrm{~nm}$ region. The degree of HTC defect could not be ascertained using this technique and requires further investigation.
\end{abstract}

\section{KEYWORDS}

Dry beans, hard-to-cook, hyperspectral imaging, discrimination, quality.

\section{RÉSUMÉ}

Des conditions non optimales d'entreposage des haricots secs peuvent créer une anomalie qui rend ceux-ci difficiles à cuire [HTC - hard to cook]. Cette anomalie augmente le temps de cuisson, entraînant une diminution de la saveur et de la valeur nutritionnelle. Les méthodes courantes pour identifier les haricots HTC prennent du temps, sont destructives et ne sont pas fiables. Une technique d'inspection rapide et non destructive pour dépister les haricots pourrait aider à identifier et éliminer les haricots HTC avant le traitement. À cette fin, le potentiel de la technique d'imagerie hyperspectrale couvrant le spectre entier visible à l'infrarouge proche (NIR) $(400-2500 \mathrm{~nm})$ a été évalué pour l'identification rapide et non destructive des haricots HTC. Des haricots blancs sains ont été traités pour reproduire artificiellement l'anomalie HTC en utilisant deux combinaisons différentes de conditions d'entreposage non optimales de température et d'humidité relative $\left(35^{\circ} \mathrm{C}, 75 \%\right.$ HR durant 45 jours et $60^{\circ} \mathrm{C}, 75 \%$ HR durant 10 jours). Ensuite, les haricots ont été cuits pendant des durées spécifiques et leur dureté a été mesurée en utilisant un analyseur de texture. Les haricots HTC et témoins (c.-à-d. facile à cuire [ETC]) ont été analysés à l'aide de systèmes d'imagerie hyperspectrale de type push-broom. Les résultats indiquent que les deux combinaisons de conditions d'entreposage ont transformé les haricots témoins en HTC, mais l'anomalie produite par les deux méthodes différentes a été détectée à différents spectres en utilisant l'imagerie hyperspectrale. Les longueurs d'onde du spectre visible entier et de celui du NIR du spectre électromagnétique ont été utiles pour détecter les haricots HTC, car les haricots entreposés à $35^{\circ} \mathrm{C}$ et $75 \%$ HR pendant 45 jours ont été identifiés principalement dans le spectre de 1000-2500 nm tandis que ceux entreposés à $60^{\circ} \mathrm{C}$ et $75 \% \mathrm{HR}$ pendant 10 jours ont été identifiés dans le spectre de 400-1000 nm. L'importance de l'anomalie HTC peut être évaluée en utilisant cette technique et des recherches additionnelles sont requises.

\section{MOTS CLÉS}

Haricots secs, cuisson difficile, imagerie hyperspectrale, discrimination, qualité.

\section{CITATION}

Diaz-Contreras, L.M., C. Erkinbaev and J. Paliwal. 2018. Non-destructive and rapid discrimination of hard-to-cook beans using hyperspectral imaging. Canadian Biosystems Engineering/Le génie des biosystèmes au Canada 60: 7.1-7.8. https://doi.org/10.7451/CBE.2018.60.7.1 


\section{INTRODUCTION}

Canada is the largest exporter of legumes in the world and Manitoba is the highest producer of dry beans in Canada. Most of this production is primarily exported to tropical regions. There is an impetus to increase the consumption of pulses as they contain a high portion of protein and other minerals to fulfill the basic dietary requirements for humans (Coelho et al. 2007). As there is a consumer demand to incorporate pulses in milled, baked, and processed foods, some quality characteristics such as protein content and non-damaged starch are important factors to consider during pulse processing (Maskus et al. 2016). One of the difficulties with dry bean consumption is the prolonged cooking time, which depending on the type of bean can extend up to several hours. These long cooking times have an adverse effect on the nutritional value and digestibility of the final product. High temperatures during cooking cause structural changes in proteins and could lead to their complete denaturation (Vanga et al. 2017). Postharvest conditions such as drying, handling, and storage influence the quality and processing characteristics of beans (Yosuf et al. 2007). During storage, beans are exposed to a variety of conditions that alter their structural and biochemical properties. During storage or transportation to export markets, agricultural products undergo changes in temperature and relative humidity $(\mathrm{RH})$ that affect their quality (Tabil and Sokhansanj 2001; Dadgar et al. 2009). One of the consequences of these changes is that beans hydrate unevenly when they are cooked after being exposed to such severe conditions (Yousif et al. 2007).

Hard-to-cook (HTC) defect is a phenomenon that develops in beans making them difficult to cook. HTC beans require more time and energy to cook, and the defect also decreases their nutritional content and palatability (Vindiola et al. 1986). The HTC phenomenon is characterized by the cotyledons within the seed not softening during cooking, even though the seed has absorbed water (Vindiola et al. 1986). HTC defect also causes failure of starch to gelatinize and the formation of insoluble pectinates (Yousif et al. 2007). Microstructure of starch granulates in cooked HTC beans differs from cooked ETC beans showing a higher proportion of deteriorated starch granulates with fissures (Parmar et al. 2017). Such beans are affected nutritionally, as it has been observed that the protein content decreases with the degree of the HTC defect (Coelho et al. 2007).

Different factors have been associated with the development of the HTC defect in grains, including genotype, growing location, storage conditions, extended storage durations, and the content of phytates and tannins (Coelho et al. 2007). One of the common causes of the HTC defect is prolonged storage with beans becoming hard to cook after long storage durations particularly under suboptimal conditions. Higher drying temperatures and suboptimal storage conditions such as high relative humidity, temperature, and time impact the degree of the HTC phenomenon; the higher these factors, the more is the time required to cook the beans (Jian et al. 2017; Coelho et al. 2007).
Agronomists and farmers use accelerated methods to detect varieties that are more prone to develop HTC phenomenon when stored or dried (Vindiola et al. 1986). When hardening beans under laboratory conditions to evaluate this phenomenon, it is necessary to mimic the field conditions that create it. This is done by exposing the beans to high RH and temperature for a given period of time (Paredes-Lopez et al. 1989). Vindiola et al. (1986) evaluated the effect of storing different varieties of beans at high temperature and RH. They observed that the increase in temperature and $\mathrm{RH}$ led to a decrease in the time required to develop HTC defect. Accelerating the hardening of beans by raising the temperature and $\mathrm{RH}$ consequently led to, browning of beans, suggesting this could be used as an indicator of hardening. Although a variety of suboptimal storage conditions can lead to hardening, it is not known if the underlying biochemical changes that cause this endresult within the beans are the same.

Different methods have been used to evaluate the development of HTC defect in beans, including the Mattson bean cooker and tactile methods (Jian et al. 2017; ParedesLopez et al. 1989). One of the tactile methods used by Vindiola et al. (1986) involved squeezing a bean between fingers and thumb to sense hard particles and graininess and determine if the bean is completely cooked. Therefore, such tactile methods are highly subjective and cannot be automated. An objective method for HTC determination is highly desired. Although Mattson bean cooker and texture analyzer provide an objective measurement, both methods are destructive, time consuming, and cannot be automated for online inspection.

Laurent et al. (2010) proposed and designed a noninvasive and rapid method to predict and detect the degree of HTC in Haricot beans. The detection was based on the relation between the change in color and the hardening of beans, which was determined by using a computerized vision system and a digital camera. HTC was developed under different conditions and it was concluded that when lower temperatures created the defect, the change in color was not noticeable to the eye.

A rapid inspection tool for pre-screening beans could help identify and discard the HTC seeds prior to processing. Hyperspectral imaging, a method that generates spatial planes with spectral variation, could offer an alternative means of rapid and non-destructive identification of HTC defect in beans. It is based on the integration of computer vision system and spectroscopy techniques that assimilates spatial images with the spectral images (Sun 2010). The short wave infrared region (1000-2500 nm) is concerned with the absorption, reflection and diffusivity of light (Ozaki et al. 2017) and relates to the overtones and combinations of $\mathrm{C}-\mathrm{H}, \mathrm{O}-\mathrm{H}$ and $\mathrm{N}-\mathrm{H}$ chemical bonds (Osborne 2000; Huang et al. 2014). The region that includes visible and near infrared wavelengths is known as the visible-to-near infrared $(400-1000 \mathrm{~nm})$ region. The spectral information can be obtained from any region of the spectra, but most studies on agricultural products utilize regions up to $1700 \mathrm{~nm}$ for the identification and discrimination of 
quality defects, such as fungus, vitreousness, and germination (Erkinbaev et al. 2017; Mahesh et al. 2015; Singh et al. 2010).

Based on a thorough review of existing literature, the objective of this project was formulated to evaluate the potential of using the entire range $(400-2500 \mathrm{~nm})$ to identify HTC defect in beans. Moreover, differences between the control or easy-to-cook (ETC) beans and those subjected to different temperatures and $\mathrm{RH}$ conditions were identified and characterized. This rapid detection technique has the potential of saving time and laborious procedures to characterize the HTC phenomenon.

\section{MATERIALS AND METHODS}

\section{Sample of white beans}

White pea beans (Phaseolus vulgaris), also known as navy beans, procured from a local Manitoba producer were used in this experiment. The initial moisture content of the beans was $12.5 \%$ (wet basis), which was measured by ovendrying the beans at $103^{\circ} \mathrm{C}$ for $72 \mathrm{~h}$ in triplicates (ASABE standard 2017).

\section{Hardening of beans}

The HTC phenomenon was artificially induced in white beans under simulated suboptimal storage conditions of high temperature and RH. In the conventional method, beans (HTC1) were stored in a container with $\mathrm{NaCl}$ solution at $75 \% \mathrm{RH}, 35^{\circ} \mathrm{C}$ for 45 days in a growth chamber (Coelho et al. 2007). In the accelerated method, beans (HTC2) were stored in a desiccator with $\mathrm{NaCl}$ solution, at $75 \% \mathrm{RH}, 60^{\circ} \mathrm{C}$ for 10 days in a conventional oven. The post-storage moisture contents of HTC1 and HTC2 beans were $15.9 \%$ and $15.7 \%$ w.b., respectively.

\section{Determination of optimal cooking time}

Beans without the hardening pre-treatment were considered as ETC beans and were used as a reference to establish the optimal cooking time. The beans were added to boiling water in an aluminum container that was heated on a hot plate. Samples of approximately 25 beans were removed from the boiling water from 30 to 65 minutes at five-minute intervals. The hardness of individual samples was measured using a LS5 texture analyzer (Lloyd materials testing, AMETEK Inc., Berwyn, PA) equipped with a $250 \mathrm{~N}$ load cell and using two cells of $50 \mathrm{~mm}$ diameter at $5 \mathrm{~mm} / \mathrm{min}$ compression speed.

A $40 \%$ compression was applied to the beans, which simulates the first bite of the molars and can be used as a quantitative measurement comparable as a reference of the acceptable tenderness by consumers (Scanlon et al. 1998). For each cooking time duration, the average force of 15 individual beans was recorded. The mean maximum forces were plotted against cooking time and the time duration. The optimal cooking time (in minutes) was defined as the time beyond which no observable change in force occurred. This optimal cooking time was then used for all subsequent experiments.

\section{Cooking of HTC samples}

Beans that were hardened by the two aforementioned methods were cooked for the optimal cooking time. HTC beans and control beans were cooked together to ensure the same cooking conditions. In order to distinguish HTC1 and HTC2 beans from control beans, a grid device made of aluminum mesh was built with 56 cells to segregate and track each individual bean within the same cooking container. The hardness of the beans subjected to suboptimal storage conditions was measured to verify the development of HTC phenomenon.

\section{Hyperspectral imaging}

One novel aspect of this study lies in that the entire visible to NIR (i.e., 400-2500 nm) spectral ranges were investigated in this study. The images in the 400-1000 nm region were acquired using a bench top hyperspectral imaging system, which consisted of a $1024 \times 896$ pixel resolution CCD camera combined with a spectrograph (SPECIM Spectral Imaging Ltd, Oulu, Finland), a translation stage with sample tray, and a light source (three quartz halogen bulbs of $30 \mathrm{~W}$ each). The imaging system was controlled by Lumo software (SPECIM Spectral Imaging Ltd, Oulu, Finland) installed on a desktop computer (Optiplex 9020, Dell, Round Rock, TX).

The hyperspectral imaging system with 1000-2500 nm range had a camera with mercury-cadmium-tellurium (HgCdTe) detector coupled with N25E spectrograph (SPECIM Spectral Imaging Ltd., Oulu, Finland) and focusing lens (OLES30) from the same manufacturer. The imaging unit was equipped with a translation stage with sample tray, a light source, and a desktop computer (Tower 3620, Dell, Round Rock, TX) with Lumo software for image acquisition and motor control. The imaging system operated in the wavelength range of 1000 and $2500 \mathrm{~nm}$ with a $384 \times 288$ pixel focal plane array.

The beans were placed in a $7 \times 8$ array on a black nonreflecting sample holder $(14 \times 17 \mathrm{~cm})$ and scanned by the camera using a motorized stage. The lights in the room were turned off prior to image acquisition to prevent any interference from stray light. The imaging system (1000$2500 \mathrm{~nm}$ ) required a minimum 30 min warming up time in order to cool the detector, whereas imaging system (400 $1000 \mathrm{~nm}$ ) needed only $10 \mathrm{~min}$. The speed of moving stage was manually set to $7 \mathrm{~mm} / \mathrm{s}$ for both units. The integration times were $20 \mathrm{~ms}$ and $7 \mathrm{~ms}$ for the imaging systems. The images after acquisition were calibrated using black and white references. Dark current was measured by completely blocking the lens and taking an image, whereas a $99 \%$ Spectralon reflectance standard (Labsphere, North Sutton, $\mathrm{NH}$ ) placed in the field-of-view of the camera was used as a white reference.

\section{Data analysis}

The images were analyzed using HYPER-Tools v.1.0 toolbox which is a graphical user interface (GUI) written in MATLAB (Mathworks Inc., Natick, MA, US) (Amigo and Mobaraki 2017). This toolbox allows processing of the entire hypercube using different classification methods. Prior to classification of the white beans in to ETC, HTC1, and HTC2 classes, spectral pre-processing was done in order to remove systematic errors and scattering effects and enhance the signal quality. In this study, the following preprocessing techniques viz., Savitzki-Golay (SG) smoothing, standard normal variation (SNV), multiplicative scatter 


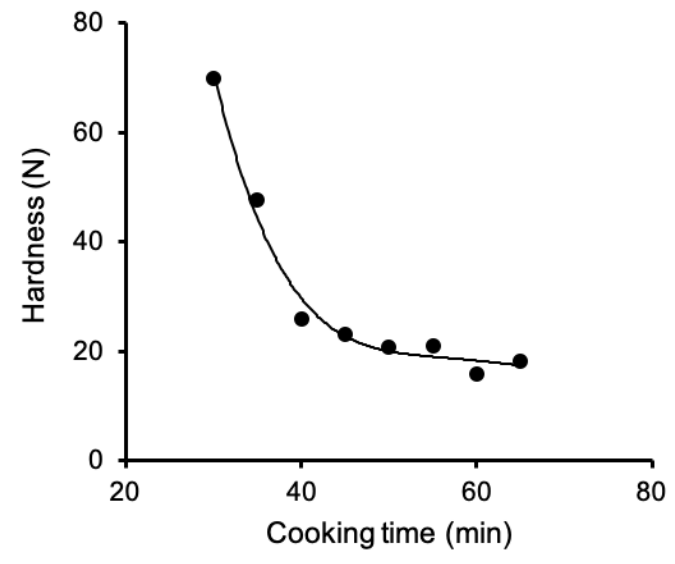

Fig. 1. Mean maximum hardness corresponding to a $40 \%$ compression of individual easy-to-cook (ETC) beans at different cooking times.

correction, and first and second order derivatives were applied and tested to accurately identify the HTC defect.

Principal component analysis (PCA) is a multivariate qualitative method that was selected to characterize the beans. PCA recognizes patterns and classifies data according to similarity metrics into groups that do not require a previously defined class (Martens and Næs 1991). Another advantage of PCA is its unsupervised learning capability, which is effective for feature selection and reduction of dimensionality of the initial dataset (Fukunaga 1990; Jiang et al. 2010). PCA transforms a dataset into its principal components (PC) that are in a lower dimensional space than the original data, yet they retain the most valuable information (Martens and Næs 1991). The objective of PCA was to generate a contrast between the ETC and HTC beans to identify patterns that can be assigned to beans and make a possible distinction between different beans and their characteristics.

As described earlier in this section, beans were scanned in arrays of $7 \times 8$. The array to build the calibration model comprised of images consisting $40 \mathrm{ETC}, 8 \mathrm{HTC} 1$, and 8 HTC2 white beans. In order to validate this model, another set of bean images comprising of randomly placed 17 HTC1, 22 HTC2, and 17 ETC beans was scanned. This dataset was replicated three times and used for validating the optimized model to differentiate the three bean groups into their respective classes.

\section{RESULTS AND DISCUSSIONS}

\section{Optimal cooking time}

For white beans that did not undergo suboptimal storage (i.e., ETC beans), the hardness decreased with prolonged cooking time (Fig. 1). The major reduction in hardness was observed between 30 and 40 min of cooking; no significant change in the mean value of maximum hardness was observed afterward $(\mathrm{p}<0.05)$. According to this trend, the optimal cooking time was identified as $40 \mathrm{~min}$ corresponding to the hardness of $25.95 \mathrm{~N}$. This result corroborates the results of a previous study where the hardness of optimal to overcooked lentils was found in the

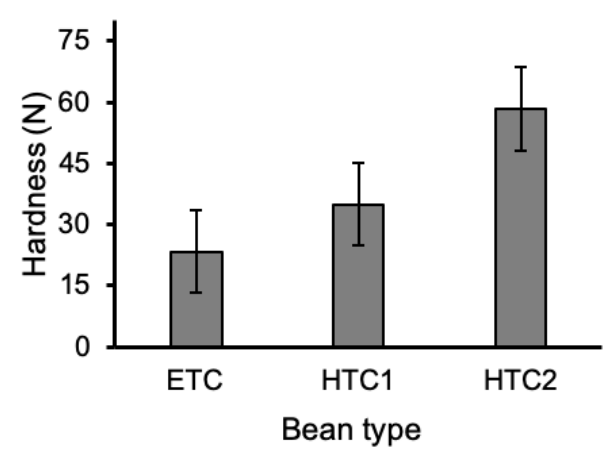

Fig. 2. Comparison of mean maximum hardness for easy-to-cook (ETC) beans, and beans hardened with the conventional (HTC1) and accelerated (HTC2) methods. All samples were cooked for $40 \mathrm{~min}$ and compressed to $\mathbf{4 0 \%}$. Error bars indicate the standard error of the mean.

range of 26 to $33 \mathrm{~N}$ using a texture analyzer (Scanlon et al. 1998). The hardness in this study and the corresponding cooking time were chosen with the sole purpose of comparing the hardness of HTC against the ETC beans when cooked for the same time.

\section{HTC development}

The development of the HTC defect was proven by measuring the hardness of the beans after cooking for 40 min, which was experimentally determined as the optimal cooking time for ETC beans. When comparing the hardness of the ETC, HTC1 and HTC2 beans, it was observed that HTC1 and HTC2 beans had higher hardness values than ETC beans (Fig. 2). The HTC1 beans (long time, low temperature, and high $\mathrm{RH}$ ) developed the HTC defect providing resistance to softening when cooked until $40 \mathrm{~min}$. The mean value of maximum hardness for HTC1, HTC2 and ETC beans was $35 \pm 6.7,58.3 \pm 13.48$ and $25.95 \pm 8.17$ $\mathrm{N}$, respectively. ANOVA test shows that there is a significant difference in hardness among the three groups of beans $(\mathrm{P}=0.0004)$. A t-test between HTC2 and ETC shows a greater difference in hardness $(\mathrm{P}<0.01)$ than the difference observed between HTC1 and ETC $(\mathrm{P}=0.04)$. Therefore, HTC2 beans (short time, high RH, and high temperature) developed a more pronounced HTC phenomenon than the HTC1 beans. Additionally, HTC2 beans developed a yellowish color, whereas the HTC1 beans had no change in color. These results show that both conventional and accelerated methods were able to produce HTC defect in the white beans.

\section{Hyperspectral images}

The processed spectra of the ETC, HTC1 and HTC2 beans in the 1000-2500 $\mathrm{nm}$ range is shown in Fig. 3. The spectra obtained in the 400-2500 $\mathrm{nm}$ range provides information about the chemical composition based on functional groups consisting of $\mathrm{C}-\mathrm{H}, \mathrm{O}-\mathrm{H}$, and $\mathrm{N}-\mathrm{H}$ bonds. Absorption bands between 1300 and $1420 \mathrm{~nm}$ correspond to $\mathrm{C}-\mathrm{H}$ combination, 1420 and $1800 \mathrm{~nm}$ correspond to $\mathrm{O}-\mathrm{H}$ and $\mathrm{N}-$ $\mathrm{H}$ first overtone and $\mathrm{C}-\mathrm{H}$ first overtone, and 1800 and 2200 $\mathrm{nm}$ correspond to $\mathrm{O}-\mathrm{H}$ and $\mathrm{N}-\mathrm{H}$ combinations (Osborne 


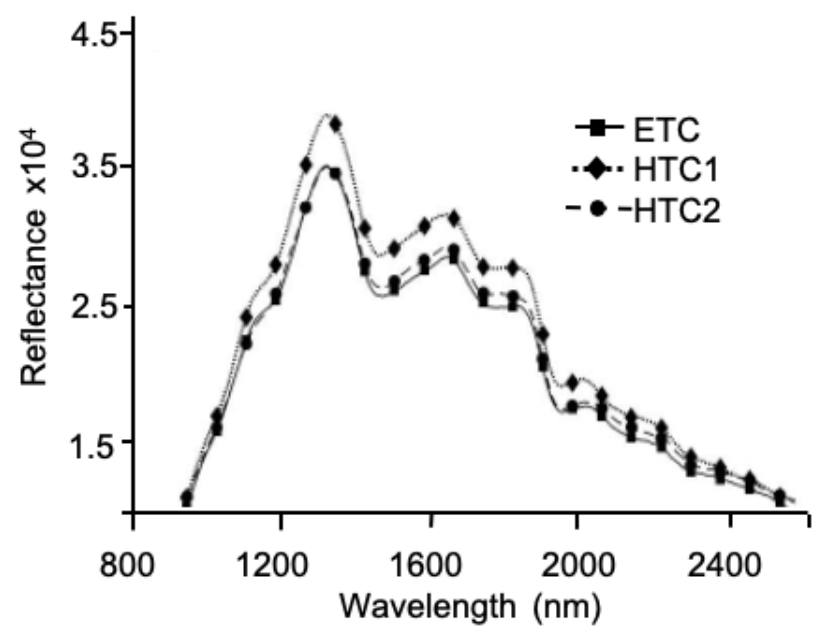

Fig. 3. Mean spectral signal of ETC, HTC1, and HTC2 beans in the $1000-2500 \mathrm{~nm}$ region.

2000). To date, most spectral studies on agricultural products have been conducted between 900-1700 nm (Mahesh et al. 2015; Wang et al. 2004). This study extends the range from $400-2500 \mathrm{~nm}$ to exploit the wealth of information that could be gleaned from the entire visible to near infrared region. The key wavelengths where differences in signal intensity among the three bean classes were observed were 1324, 1639, 1796, 1830, and $2005 \mathrm{~nm}$. Extensive spectral variations were found for HTC1 beans as compared to ETC and HTC2 beans. Hardness values related to the HTC defect measured after cooking were not proportional to the relative reflectance from the spectral information. This could be due to the different mechanisms that were involved in creating the HTC defect through the two different methods.

\section{Classification}

Different combinations of pre-processing techniques (Savitzki-Golay (SG) smoothing, standard normal variation (SNV), multiplicative scatter correction, first and second order derivatives) and evaluation of principal components were applied to the hyperspectral images to segregate HTC1, HTC2 and ETC into three groups. The best pre-

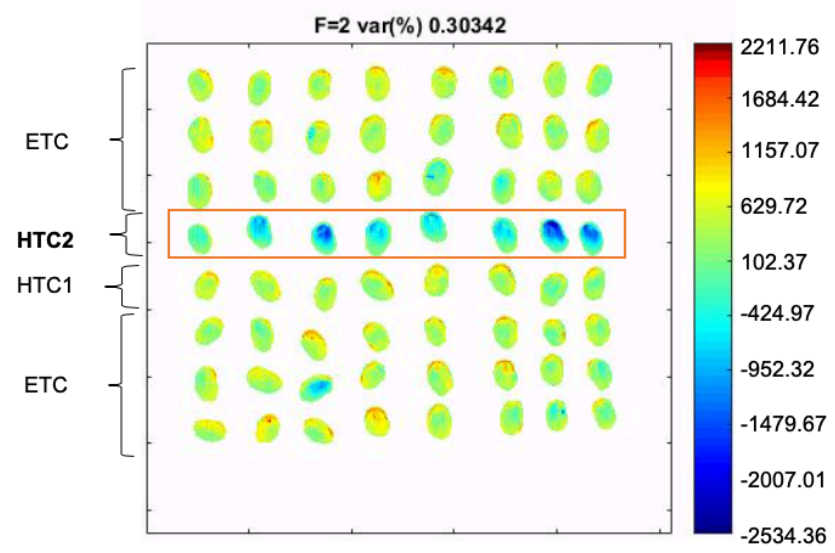

Fig 5. Classification of 56 white beans using PC 2 in the 400-1000 $\mathrm{nm}$ region showing HTC2 beans with a distinctive false colour.

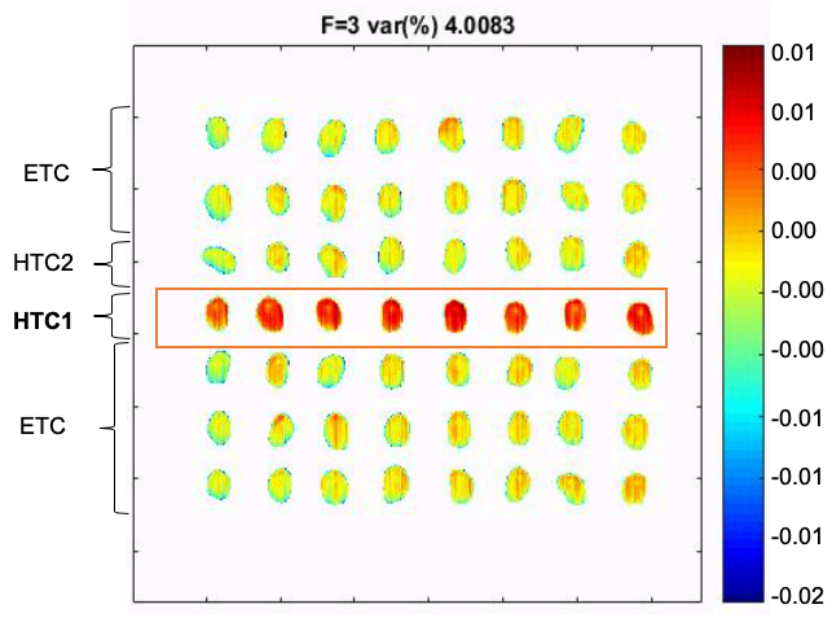

Fig 4. Classification of 56 white beans using PC 3 in the $1000-2500 \mathrm{~nm}$ region where HTC1 beans have a distinctive false colour.

processing results were obtained by removing the background using K-means clustering and then applying SNV followed by first derivative (15-window and 1-degree polynomial). Further analysis of data using PCA successfully identified $100 \%$ of HTC1 beans using PC3 (Fig. 4). Although, correct classification was obtained for HTC1, HTC2 beans could not be identified with satisfactory accuracy using this method. Therefore, another set of data analysis operation was also evaluated. Herein, SG smoothing (11-window and 1-degree polynomial) was used to pre-process the data and then pattern classification was done using PC4 and PC6. This technique resulted in similar results where $\mathrm{HTC} 1$ could be segregated from HTC2 and ETC beans; but HTC2 beans suffered from high misclassification rates. This could be attributed to the microstructural differences in the lipid polymers that are formed under the different storage conditions the two sets of beans were subjected to (Reyes-Moreno and ParedesLopez 1993). Also, beans correctly identified as HTC1 had

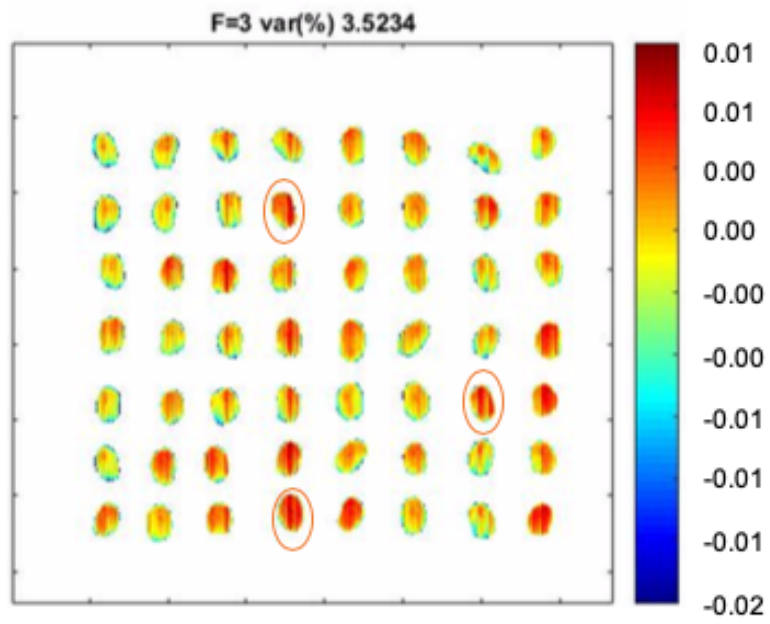

Fig. 6. Validation in the $1000-2500 \mathrm{~nm}$ region of 17 HTC1 beans randomly distributed among ETC and HTC2 beans using PC 3 with SNV and first derivative preprocessing. Example of three HTC1 beans are shown in circles. 


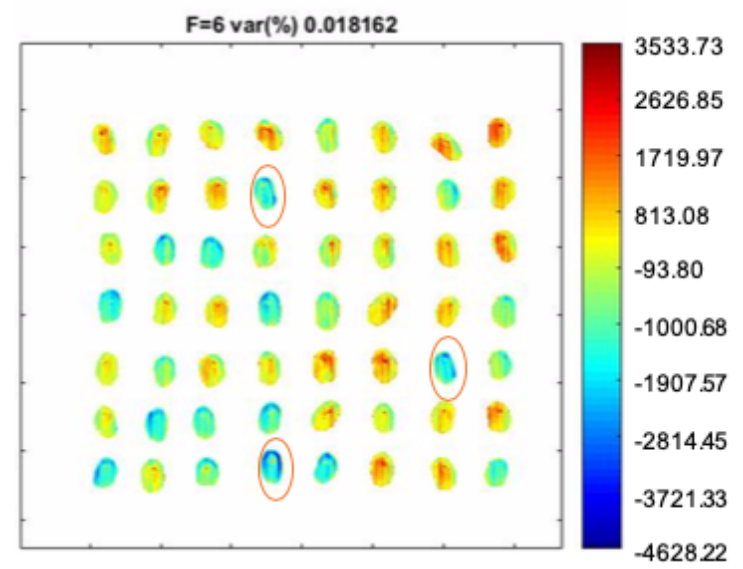

Fig. 7. Validation in the $1000-2500 \mathrm{~nm}$ region of 17 HTC1 beans randomly distributed among ETC and HTC2 beans using PC 6 with SG smoothing pre-processing. Example of three HTC1 beans are shown in circles.

different and more distinctive color intensity than that of the ETC and HTC2 beans. Another noteworthy observation here is the importance of intermediate and higher-order PCs in pattern classification. Although most researchers use lower-order PCs to account for most of the variation (Erkinbaev et al. 2007; Mahesh et al 2015), it has been established that some of the subtle variations in samples are explained by higher-order PCs (Phinyomark et al. 2015; Jolliffe 2002). In this study, the lower order PCs couldn't glean the differences among the bean classes, including the differences in moisture content between the ETC and HTC beans. However, the subtle chemical changes such as lipid oxidation, formation of pectates, and lignification of lamella (Reyes-Moreno and Paredes-Lopez 1993), that were induced by the different storage conditions could be explained only using higher order PCs. Jolliffe (2002) suggested that when intermediate and higher-order PCs are ignored, some valuable information might be lost, as not necessarily the greatest variation between groups is going to show the targeted characteristic. They also implied that when the variation within groups is larger than the variation between groups, higher-order PCs might result informative.

While the HTC1 beans were correctly identified in 1000-2500 nm spectral range, the HTC2 beans were discriminated in the 400-1000 nm range. By masking out the background and applying PCA to analyze the data, it was possible to identify the HTC2 beans from the other two classes (i.e. HTC1 and ETC) using PC2 (Fig. 5). Laurent et al. (2010) had identified and discriminated HTC beans from control beans using a digital camera by targeting the color change in beans upon the development of HTC phenomenon with accelerated methods, such as the method and conditions used on HTC2 beans of this study. These results showed that the identification of HTC phenomenon in the visible spectra can be made by relating the color change in beans observed as a result of an accelerated hardening method.

After verifying the capability of the HSI technique to differentiate the bean samples, the images of randomly-

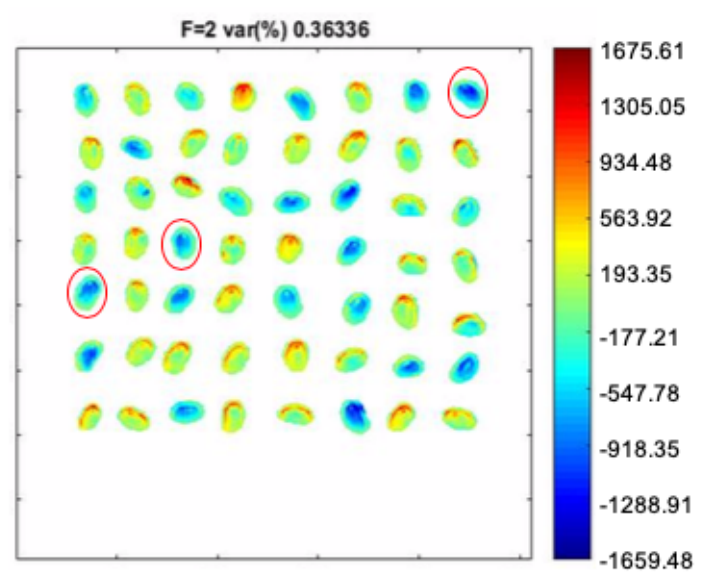

Fig. 8. Validation of PC 2 in the visible region of 22 HTC2 beans randomly distributed among ETC and HTC1 beans. Example of three HTC2 beans are shown in circles.

distributed beans were analyzed by applying the previously used pre-processing techniques. The classification accuracy for HTC1 beans using PC3 and PC6 in the 1000-2500 NM range was $100 \%$. Figure 6 and Fig. 7 show the identification of the HTC1 beans randomly distributed among ETC and HTC2 beans. The same procedure was followed for the identification of HTC2 beans in the visible spectra using PC2 (Fig. 8). In this case, all the HTC2 beans that were randomly distributed among HTC1 and ETC beans were correctly identified $(100 \%)$.

There are multiple mechanisms that attribute to the development of the HTC phenomenon such as thickening of cell wall, oxidation and polymerization of lipids, reduction in phytic acid content, etc. (Nyakuni et al. 2008, Reyes-Moreno and Paredes-Lopez 1993). These biochemical changes depend upon the storage duration, temperature, and $\mathrm{RH}$ during storage of beans. Storage conditions of high $\mathrm{RH}$ and temperature are related to the decrease in germination viability of seeds (Eliud et al. 2010), which are consequences that might appear during the developing of the HTC defect. Higher temperature and RH also increased the time to fully cook the beans, which modified the textural parameters with respect to the control samples (Garruti and Bourne 1985). Several treatments have been successfully used to demonstrate the development of HTC phenomenon in beans. These results obviate that a variety of suboptimal storage conditions combined with susceptibility of certain cultivars to hardening are responsible for the HTC defect in beans. This could be clearly seen in the wide range of wavelengths, from visible to infrared, that were required to identify beans stored under different storage conditions.

Rozo et al. (1990) investigated the biochemical changes observed in red kidney beans that were subjected to two storage conditions $\left(30^{\circ} \mathrm{C}\right.$ and $40^{\circ} \mathrm{C}$, both at $80 \% \mathrm{RH}$ for four months) in order to create the HTC defect. The authors found an increase in the cell wall content of cotyledons and also an increase in nitrogen compounds for the beans stored at $40^{\circ} \mathrm{C}$, as opposed to beans stored at $30^{\circ} \mathrm{C}$ 
and control beans, both of which did not exhibit those changes. The observed biochemical changes in the former were correlated with hardness of beans and therefore with the HTC defect.

Storage duration has been linked to the development of HTC defect along with high temperatures. Coelho et al. (2007) found that the phytate, protein and tannin contents decreased as storage time increased at $29^{\circ} \mathrm{C}$ and correlated those changes to an increase in the cooking time of common beans (Phaseolus vulgaris L.). The authors concluded that the phytate content might be used as an indication of the HTC phenomenon once the bean genotype and storage conditions were established.

While previous studies explored the spectral ranges either in the visible and near infrared, or a limited band (i.e., $1000-1700 \mathrm{~nm}$ ) this study covered the entire 400-1000 nm spectral range. While wavelengths from 400-1000 nm range were capable of identifying one set of HTC defect, the 1000-2500 $\mathrm{nm}$ region was important in segregating HTC beans created using a different set of suboptimal storage conditions. This clearly establishes that the entire visible to $1000-2500 \mathrm{~nm}$ range is necessary if an optical non-destructive method is to be used to detect HTC beans.

Given the objective of this study was to evaluate the capability of near infrared hyperspectral imaging to discriminate HTC beans, no biochemical analyses on samples were performed. Rather, the study showed that the HTC defect is a result of different suboptimal storage conditions. The fact that the beans subjected to two different conditions were detected in different spectral ranges in addition to different biochemical changes found by other authors such as phytate content and nitrogen compounds (Rozo et al. 1990; Coehlo et al. 2007), indicates that more than one underlying change is responsible for the HTC defect. The results open the door to further research that could link the wavelengths associated with specific biochemical changes to the different storage conditions that lead to HTC phenomenon.

\section{CONCLUSION}

The storage and subsequent cooking of white beans established that different suboptimal storage conditions could lead to the development of hard-to-cook (HTC) phenomenon in white beans. Two sets of suboptimal storage conditions (i.e., $35^{\circ} \mathrm{C}, 75 \% \mathrm{RH}$ for 45 days and $60^{\circ} \mathrm{C}, 75 \%$ $\mathrm{RH}$ for 10 days) were successful in developing the HTC phenomenon in beans and the hyperspectral imaging technique covering the entire visible and infrared spectral range $(400-2500 \mathrm{~nm})$ was found to be useful in identifying the HTC beans from control samples. However, it is important to note that beans hardened by storing at $35^{\circ} \mathrm{C}$, $75 \% \mathrm{RH}$ for 45 days were successfully identified in the 1000-2500 nm region, whereas HTC defect induced by storing another set of beans at $60^{\circ} \mathrm{C}$ and $75 \% \mathrm{RH}$ for 10 days was identified in the $400-1000 \mathrm{~nm}$ region. This clearly indicates that the hardening caused by different storage conditions causes dissimilar biochemical changes in the beans even though the end effect (i.e., HTC defect) is the same. The results establish that to identify the entire gamut of HTC defects caused by suboptimal storage, genotypic susceptibility, and physicochemical changes in beans, the entire visible to near infrared range is useful.

\section{ACKNOWLEDGEMENT}

The authors thank Natural Sciences and Engineering Research Council of Canada (NSERC) and Canada Foundation for Innovation (CFI) for the financial support. We also thank Dr. Rani P. Ramachandran for technical support with the texture analysis.

\section{REFERENCES}

Amigo, J. M., and N. Mobaraki. 2017. HYPER-Tools. A graphical user-friendly interface for multivariate and hyperspectral image analysis. Chemometrics and Intelligent Laboratory Systems, 172(October 2017): 174-187.

ASABE standard. 2017. S352.2: Moisture Measurement Unground Grain and Seeds. ASABE Standards. St. Joseph, Ml: ASABE Standards.

Boyd, J. V., and P. Sherman. 1975. A study of forcecompression conditions associated with hardness evaluation in several foods. Journal of Texture Studies 6(4): 507-522. https://doi.org/10.1111/j.17454603.1975.tb01424.x

Coelho, C. M. M., C. de Mattos Bellato, J. C. P. Santos, E. M. M. Ortega, and S. M. Tsai. 2007. Effect of phytate and storage conditions on the development of the "hard-to-cook" phenomenon in common beans. Journal of the Science of Food and Agriculture 87(7): 1237-1243. https://doi.org/10.1002/jsfa.2822

Dadgar, S., L.G. Tabil, W.J. Crerar, and R.A.A. Morrall. 2009. Spoilage characteristics of field pea under adverse storage conditions. Canadian Biosystems Engineering 51: 3.1-3.9.

Eliud, R., M. Reuben, and G. Linnet. 2010. Longevity of bean (phaseolus vulgaris) seeds stored at locations varying in temperature and relative humidity. Journal of Agriculture 5: 60-70.

Erkinbaev, C., K. Henderson, and J. Paliwal. 2017. Discrimination of gluten-free oats from contaminants using near infrared hyperspectral imaging technique. Food Control 80: 197-203. https://doi.org/10.1016/j.foodcont.2017.04.036

Fukunaga, K. 1990. Introduction to statistical pattern recognition, 2nd ed., New York, NY: Academic Press.

Garruti, R. D. S., and M. C. Bourne. 1985. Effect of storage conditions of dry bean seeds (phaseolus on texture profile parameters after cooking vulgaris 1). Journal of Food Science 50: 1067-1071. https://doi.org/10.1111/j.1365-2621.1985.tb13013.x

Huang, H., L. Liu, and M.O. Ngadi. 2014. Recent developments in hyperspectral imaging for assessment of food quality and safety. Sensors 14(4): 7248-7276. https://doi.org/10.3390/s140407248

Jolliffe, I. T. 2002. Principal Component Analysis, 2nd ed. New York: Springer.

Jian, F., D. S. Jayas, P. G. Fields, and N. D. G. White. 2017. Water sorption and cooking time of red kidney beans ( Phaseolus vulgaris L.): part II - mathematical models of water sorption. International Journal of Food Science \& Technology 52(11): 2412-2421. https://doi.org/10.1111/ijfs.13525 
Jiang, L., B. Zhu, and Y. Tao. 2010. Hyperspectral image classification methods. In Hyperspectral Imaging for Food Quality Analysis and Control, ed. D-W Sun, 7998. Academic Press. https://doi.org/10.1016/B978-012-374753-2.10003-6

Laurent, B., B. Ousman, T. Dzudie, M. F. M. Carl, and T. Emmanuel. 2010. Digital camera images processing of hard-to-cook beans. Jornal of Engineering and Technology Research 2(9): 177-188.

Mahesh, S., D. S. Jayas, J. Paliwal, and N. D. G. White. 2015. Hyperspectral imaging to classify and monitor quality of agricultural materials. Journal of Stored Products Research 61: 17-26. https://doi.org/10.1016/j.jspr.2015.01.006

Martens, H. A., \& Næs, T. (1991). Multivariate Calibration (1st ed.). Chichester: Wiley.

Maskus, H., L. Bourré, S. Fraser, A. Sarkar, and L. Malcolmson. 2016. Effects of grinding method on the compositional, physical, and functional properties of whole and split yellow pea flours. Cereal Foods World 61(2):59-64. https://doi.org/10.1094/CFW-612-0059

Nyakuni, G.A., J.K. Kikafunda, J.H. Muyonga, W.M. Kyamuhangire, D. Nakimbugwe, and M. Ugen. 2008. Chemical and nutritional changes associated with the development of the hard-to-cook defect in commom beans. International Journal of Food Sciences and Nutrition 59(7-8): 652-659. https://doi.org/10.1080/09637480701602886

Osborne, B. G. 2000. Near-Infrared Spectroscopy in Food Analysis. In Encyclopedia of Analytical Chemistry, 114. John Wiley \& Sons, Ltd. https://doi.org/10.1002/9780470027318.a1018

Ozaki, Y., T. Genkawa, and Y. Futami. 2017. Near-Infrared Spectroscopy. In Encyclopedia of Spectroscopy and Spectrometry (3rd ed.), eds., J. C. Lindon, G. E. Tranter and D. W. Koppenaal, 40-49. Elsevier Ltd. https://doi.org/10.1016/B978-0-12-409547-2.12164-X

Paredes-López, O., C. Reyes-Moreno, R. Montes-Rivera, and A. Carabez-Trejo. 1989. Hard-to-cook phenomenon in common beans- influence of growing location and hardening procedures. International Journal of Food Science \& Technology 24(5): 535542. https://doi.org/10.1111/j.1365-2621.1989.tb00677.x

Parmar, N., N. Singh, A. Kaur, A. S. Virdi, and K. Shevkani. 2017. Protein and microstructure evaluation of harder-to-cook and easy-to-cook grains from different kidney bean accessions. LWT - Food Science and Technology 79: 487-495. https://doi.org/10.1016/j.lwt.2017.01.027

Phinyomark A, B.A. Hettinga, S. Osis, R. Ferber. 2015. Do intermediate-and higher-order principal components contain useful information to detect subtle changes in lower extremity biomechanics during running?. Human Movement Science 44 :91-101. https://doi.org/10.1016/j.humov.2015.08.018
Reyes-Moreno, C., and O. Paredes-López. 1993. Hard-tocook phenomenon in common beans-a review. Critical Reviews in Food Science and Nutrition 33(2): 227-286. https://doi.org/10.1080/10408399309527621

Rozo, C., M.C. Bourne and L.F. Hood. 1990. Effect of storage time, relative humidity and temperature on the cookability of whole red kidney beans and on the cell wall components of the cotyledons. Canadian Institute of Foood Science and Technology 23(1): 7275. https://doi.org/10.1016/S0315-5463(90)70203-9

Scanlon, M. G., L. J. Malcolmson, S. D. Arntfield, B. Watts, D. Ryland, and D. J. Prokopowich. 1998. Micronization pretreatments for reducing the cooking time of lentils. Journal of the Science of Food and Agriculture 76: 23-30.

https://doi.org/10.1002/(SICI)10970010(199801)76:1<23::AID-JSFA913>3.0.CO;2-9

Singh, C.B., D.S. Jayas, J. Paliwal, and N.D.G. White. 2010. Detection of midge-damaged wheat kernels using short-wave near-infrared hyperspectral and digital colour imaging. Biosystems Engineering 105(3):380-387.Sun, D-W. 2016. Computer Vision Technology for Food Quality Evaluation, 2nd ed. Academic Press.

Sun, D. W. 2010. Hyperspectral Imaging for Food Quality Analysis and Control. In Hyperspectral Imaging for Food Quality Analysis and Control, ed. D-W Sun, 7998. Academic Press.

Tabil, L.G. and S. Sokhansanj. 2001. Mechanical and temperature effects on shelf life stability of fruits and vegetables. In Food Shelf life Stability-Chemical, Biochemical and Microbiological Changes, eds. N.A.M. Eskin and D.S. Robinson, 38-39. Florida, USA: CRC Press.

Vanga, S.K., A. Singh, and V. Raghavan. 2017. Review of conventional and novel food processing methods on food allergens. Critical Reviews in Food Science and Nutrition 57(10): 2077-2094. https://doi.org/10.1080/10408398.2015.1045965

Vindiola, O. L., P. A. Seib, and R. C. Hoseney. 1986. Accelerated development of the hard-to-cook state in beans. Cereal Foods World 31: 538-552.

Wang, D., F. E. Dowell, M. S. Ram, and W. T. Schapaugh. 2004. Classification of fungal-damaged soybean seeds using near-infrared spectroscopy. International Journal of Food Properties 7(1): 75-82. https://doi.org/10.1081/JFP-120022981

Wang, L., D. Liu, H. Pu, D. W. Sun, W. Gao, and Z. Xiong. 2014. Use of hyperspectral imaging to discriminate the variety and quality of rice. Food Analytical Methods 8(2): 515-523. https://doi.org/10.1007/s12161-014-9916-5

Yousif, A. M., J. Kato, and H. C. Deeth. 2007. Effect of storage on the biochemical structure and processing quality of adzuki bean (Vigna angularis). Food Reviews International 23(1): 1-33. https://doi.org/10.1080/87559120600865172 